\title{
Identificación y análisis de las características identitarias de la empresa social europea: aplicación a la realidad de los Centros Especiales de Empleo de la economía española
}

\section{José Luis Monzón-Campos y Mercedes Herrero-Montagud}

\section{RESUMEN}

Ante los principales desafíos de las sociedades actuales el concepto de empresa social se percibe como una respuesta innovadora y dinámica, siendo objeto de un interés y atención creciente desde el ámbito académico, profesional y político. Sin embargo, a pesar del importante desarrollo que ha tenido el concepto de empresa social en los últimos años, todavía no existe una definición compartida por los investigadores comprometidos en el estudio de este fenómeno.

Este artículo presenta, -a partir del análisis de los principales enfoques y corrientes de pensamiento que rodean al concepto de empresa social y del examen de su realidad conceptual y normativa en los países de la Unión Europea-, un conjunto de características identitarias básicas que permiten identificar a las empresas sociales y diferenciarlas de otras organizaciones en el ámbito europeo. La aplicación de este conjunto de características identitarias a la realidad de los Centros Especiales de Empleo (CEE) de la economía española, ha permitido demostrar que no todos esos centros pueden ser identificados como empresas sociales sino únicamente los CEE de la Economía Social, llegando a la conclusión de que existen elementos suficientes para delimitar a las empresas sociales del resto de operadores económicos.

PALABRAS CLAVE: Economía Social, empresa social, carcaterísticas identitarias, Centros Especiales de Empleo.

CLAVES ECONLIT: A13, J14, M29.

Cómo citar este artículo / How to cite this article: MONZÓN-CAMPOS, J.L. \& HERREROMONTAGUD, M. (2016): "Identificación y análisis de las características identitarias de la empresa social europea: aplicación a la realidad de los Centros Especiales de Empleo de la economía española", CIRIEC-España, Revista de Economía Pública, Social y Cooperativa, 87, 295-326.

Correspondencia: José Luis Monzón-Campos, Catedrático de Economía Aplicada, Universidad de Valencia, J.Luis.Monzon@uv.es; Mercedes Herrero-Montagud, Profesora Titular, Florida Universitaria (Universidad de Valencia), mherrero@ florida-uni.es. 


\section{EXPANDED ABSTRACT}

\section{Identification and analysis of the basic identity characteristics of European social enterprise: Application to the reality of Sheltered Employment Centers of the Spanish economy}

\section{Purpose}

During the last twenty years the social enterprise has seen a noticeable expansion in the European Union together with a proliferation of concepts and terms seeking to define and distinguish it from the traditional enterprise, both in the public and private sectors and in the Social Economy. However, despite the significant development of the concept of social enterprise, there is not yet a shared definition by researchers engaged in the study of this phenomenon. In this regard, this paper firstly aims to propose a set of basic identity characteristics that allows to delimit and to identify the social enterprise in Europe. Moreover, it targets to establish some basic principles that identify and distinguish the social enterprise from any other organizations. The characterization of certain Sheltered Employment Centres (SEC) as social enterprise, from the set of characteristics proposed, is part of the second aim.

\section{Design/Methodology/Approach}

Given the conceptual and terminological diversity around the concept of social enterprise, it is necessary to order and analyse the main approaches and dimensions around this concept in the scientific field, comparing their main differences and similarities.

Besides the definitions of social enterprise proposed in the academic field, the definitions used within countries are specific to what is meant at a national level by the phenomenon of social enterprise. This has led countries to develop their own definitions and legal frameworks. Hence, it is also necessary to analyse the conceptual reality and legislation of the social enterprise present in the European Union member countries that have developed some form of legislation recognizing and regulating its activity. The focus is placed on the main characteristics that can be noticeable in each of them and on the identification of the most consistent social enterprise models developed at EU level.

The review and analysis of these two issues (academic literature and conceptual reality and regulations in the European Union countries), has constituted the theoretical basis for the proposed set of basic identity characteristics of the social enterprise in Europe.

Finally, those identity characteristics are used to characterize some Sheltered Employment Centres (SEC) as social enterprises, using mainly quantitative and qualitative information provided by the work 
carried out by CIRIEC-Spain about SEC: type of SEC, aggregate accounts (balance sheet, profit and loss account), employment...

\section{Findings}

The social enterprise is an operator of the Social Economy that presents five basic identity characteristics. Firstly, they are private organizations created to solve a problem or social need of general interest and which obtain social and economic value maximizing either their profits or social impact. Secondly, they face social needs in a direct way by producing goods and services at economically significant prices, being their activity directly related to the social purpose. Thirdly, they operate with a business approach, i.e. they develop their activities with a minimum amount of remunerated work; they assume the economic risk inherent in their activity combining suitably resources that allow them to be viable and sustainable (the commercial activity revenue being a significant part of them); they are also autonomous from the State and other traditional profit organizations. Fourthly, although social enterprises do not have to be non-for-profit organizations, they must reinvest part of their profits. Finally, they adopt organizational structures that ensure compliance with the social purpose, including democratic and participatory principles that can be combined with elements of governance characteristic of profit organizations.

In addition, the combination of these five characteristics permits to distinguish social enterprises from other types of organization. Social enterprises differ from traditional profit organizations, Social Action Third Sector organizations, charities commercial subsidiaries, and most Social Economy market producers.

One of the fields of activity of social enterprises is the training and integration in employment of either people excluded from the labour market or vulnerable groups by means of permanent or temporary employment in firms with a social dimension that trade in the market. In order to refer to this kind of labour integration initiatives within the social economy, a specific term has arisen in Europe, Work Integration Social Enterprises, i.e. WISE. In Spain, SECs and Integration Enterprises are the main examples of WISEs.

SECs are market producers that can take all kinds of legal frameworks. According to their main objectives and ownership, the study carried out by CIRIEC-Spain classifies them into Social Economy SECs, Public Economy SECs, and Capitalist Economy SECs. Neither Public Economy SECs (since they are publicly owned) nor Capitalist Economy SECs (as they do not belong to the social economy) can be considered social enterprises. Therefore, henceforth we will focus on Social Economy SECs.

Social Economy SECs are privately owned centres whose explicit general interest social purpose is to provide disabled people with a remunerated and productive job as well as to facilitate their integration into the regular labour market. Although the social purpose is the same in all SECs, this is a priority for Social Economy SECs, as indicated through their rates of return, much lower than those of Capitalist Economy SECS. 
Social Economy SECs develop an ongoing economic and market-oriented activity which is directly related to their social purpose in the way in which their production is carried out. They also use remunerated work and assume financial risk by obtaining a mix of suitable resources to undertake their activity, representing their sales revenue $68 \%$ of their total revenues. Social Economy SECs identified by CIRIEC-Spain's research verify the identity criteria of the Social Economy, including the priority of allocating profits to the social purpose. Finally, although carrying out democratic and participatory governance in SECs can be very complicated due to the nature of the target population of these centres, compliance with the social purpose is guaranteed as SECs regulation states that their structure and organization must safeguard their social function.

Although it is considered that the conceptual and theoretical foundations on which the proposed set of identity characteristics of social enterprise are enough, the need for further development and maturation is acknowledged.

\section{Conclusions / Original Value}

Based on the review and analysis of academic literature as well as on the conceptual and legislative framework in the EU countries, this paper has proposed a set of basic identity characteristics that allows to delimit and to identify the social enterprise in Europe. These have led to the conclusion that the European social enterprise is an operator of the Social Economy that verifies its principles and also develops its business in the market, from which its main source of income stems. Moreover, the combination of these characteristics enables the exclusion of other forms of organization in the concept of social enterprise.

The application of this set of basic identity characteristics of social enterprises to the reality of Sheltered Employment Centres of the Spanish Economy has shown that not all of them can be identified as social enterprises but only Sheltered Employment Centres of Social Economy, reaching the conclusion that there are enough elements to delimit the social enterprise from other economic organizations.

Therefore, further work is needed to reach a consensus on what social enterprises are and are not so that we can identify and establish different types or profiles of social enterprises in each country, gathering their own or specific characteristics. This is the only way in which concise sector statistics can be built that will allow, together with appropriate indicators, to measure and assess the size and impact of this sector and its efficiency, offering as well to establish specific policy actions that will enable to benefit from the wealth and diversity of social enterprises.

KEYWORDS: Social Economy, social enterprise, identity characteristics, Sheltered Employment Centers. 


\section{1.- Introducción}

La reciente crisis económica y financiera ha enfrentado a todos los países de la Unión Europea a problemas económicos y sociales complejos que, junto a los cambios demográficos que se están produciendo, plantean importantes retos a los sistemas de protección social. Ante estos retos es necesario buscar y promover sistemas innovadores que permitan garantizar la prestación de servicios sociales de manera eficiente. Si bien hay opiniones que sostienen que el aumento de necesidades sociales en bienes preferentes aconsejan la externalización de su provisión y financiamiento, (ante la "dificultad" de que el Estado asuma esos costes), otros opinan que la solución no pasa por reducir la "responsabilidad pública frente a los problemas sociales", (Gilbert, 2002), sino por buscar formas más eficientes de afrontar dichos problemas, entre las cuales estaría el apoyo a nuevas formas de acción empresarial ${ }^{1}$. Es decir, el apoyo a organizaciones de la sociedad civil que conviertan los problemas sociales en sus principales objetivos y los consigan operando en el mercado y de la forma más eficiente, es decir, llegando al mayor número de personas, de la mejor forma posible y utilizando la menor cantidad de recursos públicos. Esta última vía de apoyo significa un cambio en la modalidad de intervención del Estado y un mayor compromiso de la sociedad civil.

La "Iniciativa en favor del emprendimiento social" 2 considera a las empresas sociales como elementos fundamentales del Estado de Bienestar por su contribución a la prestación de servicios sociales, la promoción de la buena gobernanza y su contribución a una sociedad más cohesionada, democrática y activa. Así mismo, la "Estrategia Europa 2020"3, señala que las empresas sociales tienen el potencial de innovación y la capacidad para responder a las necesidades sociales y humanas que no cubren de forma suficiente o satisfactoria los operadores comerciales o el Estado.

La realidad es que la empresa social es objeto de un interés y una atención creciente en el ámbito académico, profesional y político. El concepto de empresa social se percibe como una respuesta innovadora y dinámica a los principales desafíos que presentan las sociedades actuales, (Defourny, Hulgrad y Pestoff, 2014). Sin embargo, no existe un acuerdo generalizado en la literatura científica sobre las características identitarias de la empresa social, dando lugar a una diversidad conceptual y a cierta confusión terminológica.

1.- Tal y como señalan Defourny, Hulgard y Pestoff (2014), existen en la actualidad dos escenarios alternativos en relación a la provisión de servicios de bienestar en Europa: el New Public Management, con privatización no regulada, o el New Public Governance, con un mayor pluralismo del bienestar. Este último escenario otorga un mayor papel al Tercer Sector/Economía Social como alternativa a los proveedores de servicios de bienestar públicos y lucrativos.

2.- Comisión Europea, "Iniciativa en favor del emprendimiento social", COM (2011), Bruselas.

3.- Comisión Europea, "Europa 2020: Una estrategia para un crecimiento inteligente, sostenible e integrador", COM (2010), Bruselas. 
Ante esta situación se hace necesario buscar un significado compartido de empresa social 0 , por lo menos, un acuerdo al menos parcial del término y de sus principales características, que permita otorgar credibilidad a aquellas organizaciones que prestan sus servicios bajo los auspicios de ser empresas sociales a la vez que identificar las cualidades 0 atributos distintivos y que mejor explican la empresa social en diferentes contextos. El consenso sobre cómo definir y delimitar la naturaleza de la empresa social es indispensable para poder obtener información estadística concisa sobre el sector, y para el desarrollo de un cuerpo consistente de investigación (Heckl, 2007; Young y Lecy, 2012).

En este sentido el primer objetivo de este artículo es proponer un conjunto de características identitarias básicas de la empresa social que permitan su delimitación y diferenciación respecto a otras organizaciones en el ámbito europeo. Se trata de establecer unos principios fundamentales que permitan identificar a las empresas sociales y diferenciarlas de cualquier otro tipo de organizaciones. La caracterización de determinados Centros Especiales de Empleo (CEE) como empresas sociales, a partir del conjunto de indicadores propuestos, forma parte del segundo objetivo ${ }^{4}$.

El artículo se estructura de la siguiente forma. En el apartado 2, se realiza un examen de la literatura relacionada con los principales enfoques y corrientes de pensamiento en torno al concepto de empresa social. En el tercer apartado, se analiza la realidad conceptual y normativa de la empresa social en aquellos países de la Unión Europea que han desarrollado alguna forma de legislación que reconoce y regula su actividad. Los dos apartados anteriores constituyen la base teórica para la propuesta del conjunto de características identitarias básicas de la empresa social en Europa que se realiza en el cuarto apartado. En el quinto apartado se procede a utilizar dichas características identitarias para caracterizar a determinados Centros Especiales de Empleo como empresas sociales y, por último, se presentan las conclusiones más relevantes.

\section{2.- El debate científico sobre el concepto de empresa social}

A pesar del desarrollo de iniciativas empresariales con carácter social y de la búsqueda de definiciones para este nuevo tipo de organizaciones, tanto en Europa como en Estados Unidos, nos encontramos en la actualidad sin un concepto ampliamente aceptado de empresa social, enfrentándonos a diversas definiciones y a una confusión terminológica agravada por el uso de diferentes formas legales alrededor del mundo.

4.- Este artículo es parte de la Tesis Doctoral titulada "Las empresas sociales: un grupo en expansión en el ámbito de la Economía Social. Identificación y análisis de las características identitarias de la empresa social en Europa y su aplicación a los Centros Especiales de empleo de la economía española", realizada por Dña. Mercedes Herrero Montagud y dirigida por D. José Luis Monzón Campos (Valencia, diciembre de 2015). 
La literatura académica ha detectado dos enfoques o tradiciones principales en relación a la empresa social (Galera y Borzaga, 2009): el enfoque europeo continental y el enfoque norteamericano. El enfoque europeo continental, vinculado al enfoque EMES5, está asociado con el redescubrimiento del papel de las organizaciones no lucrativas en la provisión de servicios y en la integración laboral, e incluye a la empresa social dentro del marco de los principios y valores de la Economía Social. El enfoque norteamericano enfatiza la generación de ingresos señalando que la actividad de las empresas sociales surge a menudo cuando se recorta la financiación de las organizaciones no lucrativas, exigiéndoles entonces la generación de ingresos a través de la actividad comercial que puede estar o no relacionada con su misión social.

La influencia que el desarrollo conceptual de la empresa social en el Reino Unido ha tenido en la política pública de otros países, así como en diversos estudios internacionales, ha llevado a algunos autores a hablar del enfoque británico (Defourny, 2014; Ridley-Duf y Bull, 2011), que considera que las empresas sociales son organizaciones impulsadas principalmente por objetivos sociales que logran sostenibilidad a través del comercio.

\subsection{La empresa social en el enfoque europeo: EMES y el enfoque británico}

\section{1.a. El enfoque EMES}

"Las empresas sociales son organizaciones privadas no lucrativas que proporcionan bienes y/o servicios directamente relacionados con su objetivo explícito de beneficio a la comunidad. Descansan en dinámicas colectivas que implican a varios grupos de interés en sus órganos de gobierno, tienen un alto grado de autonomía y soportan riesgos económicos ligados a su actividad"' (Defourny y Nyssens, 2008:5).

La propuesta de empresa social de EMES se fundamenta en un conjunto de indicadores económicos y sociales que Defourny y Nyssens (2014) presentan en tres subconjuntos, en lugar de los dos subconjuntos habitualmente utilizados, señalando que de esa forma se puede adoptar una perspectiva comparada con las escuelas de pensamiento de Estados Unidos así como reconocer más fácilmente algunas de las características habituales de la Economía Social redefinidas en estos criterios, identificando de esta manera nuevas dinámicas empresariales surgidas en su seno. Este conjunto de criterios económicos y sociales no debe ser considerado como las condiciones a cumplir por una organización para ser calificada como empresa social, sino más bien como un instrumento de ayuda que permita establecer los límites del conjunto de organizaciones que pueden ser consideradas como empresas sociales (Deforuny y Nyssens, 2014; Galera y Borzaga, 2009). La Tabla 1 recoge estos criterios.

5.- El acrónimo EMES viene de "Emergence des Enterprises Sociales en Europe", título en francés del trabajo de investigación llevado a cabo por la red desde 1996 hasta el año 2000. El acrónimo fue retenido cuando la red decidió convertirse en una asociación internacional formal y llevó a cabo otros proyectos de investigación sobre empresas sociales, y de forma más amplia sobre el Tercer Sector. 
Como señalan Defourny y Nyssens, estos indicadores pueden ayudar a identificar nuevas empresas sociales $y$, además, pueden designar como empresa social a antiguas organizaciones reconfiguradas por nuevas dinámicas internas.

\section{Tabla 1. Criterios definición empresa social enfoque EMES}

\begin{tabular}{|l|l|l|}
\hline Dimensión económica y empresarial: & Dimensión social: & Dimensión participativa: \\
- Actividad continuada de producción & - Objetivo explícito de & - Autonomía \\
de bienes o prestación de servicios & beneficio a la comunidad & - Poder de decisión no basado \\
- Nivel significativo de riesgo económico & - Iniciativa colectiva & en la propiedad del capital \\
- Cantidad mínima de trabajo remunerado & - Límite a la distribución de beneficios & -Naturaleza participativa \\
\hline
\end{tabular}

FUENTE: Elaboración Propia.

\section{1.b. El enfoque británico}

La definición oficial de empresa social fue utilizada por primera vez por el gobierno británico en el informe "Empresa y Exclusión", realizado en 1999 por la Neighbourhood Renewal Unit UK. Pero no fue hasta el año 2002 cuando el Departamento de Industria y Comercio del Reino Unido (Department of Trade and Industry, DTI), publica una definición de empresa social:

"empresa con objetivos prioritariamente sociales, cuyos beneficios se reinvierten principalmente para ese propósito en el negocio o en la comunidad, en lugar de iniciativas impulsadas por la necesidad de maximizar el beneficio para los accionistas 0 dueños" (Department of Trade and Industry, 2004:13).

En esta definición se aceptan algunos de los criterios del enfoque EMES ( beneficio a la comunidad, poder de toma de decisiones no basado en la propiedad de capital, distribución limitada de beneficios, actividad económica continuada), se rechazan otros criterios de dicho enfoque como requerimientos legales (naturaleza participativa) y se dejan otros criterios imprecisos (riesgo económico, autonomía, implicación ciudadana, cantidad mínima de trabajo remunerado) (Ridley-Duff y Bull, 2011). Otra característica implícita en esa definición es la diversidad y multiplicidad de formas organizativas que se pueden dar en las empresas sociales.

Basándose en esa definición se llevaron a cabo por todo el país una serie de estudios empíricos cuya síntesis se recogió en un informe encargado por la Social Enterprise Unit, (Ecotec 2003), que señalaba la inoperatividad de la definición debido a dificultades de consistencia y compatibilidad y, recomendaba, con el objetivo de corregir tales deficiencias, descomponer la definición en un conjunto de características o criterios que deberían ser más útiles en la elaboración de un inventario de empre- 
sas sociales en el Reino Unido (Defourny, 2014). De este modo, la Social Enterprise Coalition, propuso utilizar tres criterios principales: orientación de mercado, objetivos sociales y un tercer criterio de propósito social definido por una estructura de gobernanza y propiedad basada en la participación y control por grupos de interés o por administradores o directores. Sin embargo, a pesar de los esfuerzos conceptuales, los criterios utilizados en estudios posteriores variaron. En particular, el criterio relacionado con la proporción que el ingreso obtenido del mercado representa en los ingresos totales de la empresa social y el marco legal bajo el cual la empresa es registrada.

En medio de esas dificultades conceptuales y prácticas, en el año 2010 surge la Social Enterprise Mark, (SEM), con el propósito principal de defender la "marca empresa social" de organismos financiados por el gobierno y de organizaciones del sector voluntario que ni son autónomas ni persiguen sus objetivos sociales a través del comercio, además de evitar que corporaciones privadas aleguen ser empresas sociales sobre la base de actividades de apoyo a la comunidad, (Ridley-Duff y Southcombe, 2012). Los criterios desarrollados para identificar a una organización como empresa social fueron: (i) Objetivos sociales y medioambientales evidenciados en documentos constitutivos; (ii) Organización independiente y legalmente constituida, con gobierno autónomo; (iii) El 50\% o más de las ganancias deben proceder del comercio, con evidencia sobre la utilización de "prácticas de contabilidad estándar"; (iii) EL 50\% o más de los beneficios de la organización deben destinarse a los objetivos sociales y medioambientales de la organización; (iv) En caso de disolución los activos residuales se destinan a propósitos sociales y medioambientales; (v) Demostrar el logro de los objetivos sociales y medioambientales.

En la actualidad sigue abierto el debate en torno al concepto de empresa social en Reino Unido. Sin embargo, a pesar de la diversidad de criterios utilizados por los diferentes estudios llevados a cabo, parece existir cierto consenso en relación a dos criterios principales que forman parte de la identidad de las empresas sociales en el Reino Unido: son organizaciones comerciales que priorizan objetivos sociales, es decir, organizaciones impulsadas principalmente por objetivos sociales que logran sostenibilidad a través del comercio. Diversos documentos y estudios académicos del Reino Unido señalan que las empresas sociales deben obtener como mínimo el 50\% de sus ingresos del comercio como referente para distinguir a las organizaciones caritativas -que utilizan el comercio para complementar sus ingresos-, de las empresas sociales -que utilizan el comercio para perseguir su objetivo social(Ridley-Duff y Southcombe 2012). Esas dos características quedan reflejadas en la definición de empresa social que ofrece Social Enterprise UK (SEUK $\left.{ }^{6}\right)$, que establece criterios de identificación de la empresa social similares a los establecidos por SEM. 


\subsection{La empresa social en el enfoque norteamericano: las principales escuelas de pensamiento en Estados Unidos}

Dada la diversidad de conceptos y definiciones utilizados desde principios de los años ochenta en Estados Unidos para describir comportamientos empresariales con objetivos sociales -que se desarrollaron en el país principalmente, aunque no exclusivamente, dentro del sector no lucrativo-, Dees y Anderson (2006) proponen una tipología que distingue dos escuelas principales de pensamiento en relación al concepto de empresa social. La primera escuela de pensamiento, "Earned Income", representada entre otros por Jerr Baschee del Instituto de Emprendedores Sociales y Jim McClurg de Social Enterprise Alliance, enfatiza la centralidad del "ingreso ganado", es decir, se refiere al uso de actividades comerciales por organizaciones no lucrativas en apoyo de su misión. La segunda escuela, conducida por organizaciones como Ashoka y por Greg Dees de la Universidad de Stanford, está basada en una visión más amplia del espíritu empresarial. Se centra en las empresas sociales como innovación e impacto social: es la llamada escuela de "Innovación Social".

\section{2.a. La escuela "Earned Income"}

Defourny y Nysenss (2014), sugieren distinguir dentro de esta primera escuela de pensamiento entre una primera versión, "Commercial Non-Profit", centrada en organizaciones sin fines de lucro y una versión más ampliada "Mission-Driven Business", que abarca todas las formas de iniciativa empresarial.

La primera versión, "Commercial Non-Profit", localiza las empresas sociales en el ámbito de las organizaciones no lucrativas, es decir, las empresas sociales son organizaciones que retienen totalmente sus excedentes para el cumplimiento de su misión social. La actividad comercial se considera como fuente de ingresos y no importa la naturaleza de los bienes y servicios comercializados, es decir, las empresas sociales pueden desarrollar cualquier actividad de negocio aunque dicha actividad sólo esté relacionada con su misión social por los recursos financieros que asegura. La segunda versión de esta escuela, "Mission-Driven Business", se centra en una visión más amplia que abarca a todas las formas de iniciativas de negocio, es decir, hace referencia al campo de las empresas con propósitos sociales incluyendo, por tanto, todas aquellas organizaciones que comercian con un propósito social, incluyendo compañías lucrativas?.

7.- Esta segunda versión hace que surjan cuestiones conceptuales fundamentales como es la cuestión de si se puede considerar cualquier actividad generadora de valor social como expresión de iniciativa empresarial social incluso aunque dicha actividad sea marginal dentro de la estrategia global de la empresa (Defourny y Nyssens, 2014). 


\section{2.b. La escuela "Innovación Social"}

Esta segunda escuela de pensamiento pone énfasis en el perfil y en el comportamiento de los emprendedores sociales desde una perspectiva Schumpeteriana, tal y como fue definida por el trabajo de Young (1986). Los emprendedores en el sector no lucrativo son "responsables de cambios" al llevar a cabo "nuevas combinaciones" en al menos uno de los siguientes aspectos: nuevos servicios, nuevas calidades de los servicios, nuevos métodos de producción, nuevos factores de producción, nuevas formas de organización o nuevos mercados. El espíritu empresarial social puede entonces tener más que ver con los resultados y el impacto social que con la obtención de ingresos. Varias fundaciones implicadas en la "filantropía empresarial", como Schwab Foundation y Skoll Foundation, han adoptado la idea de que la innovación social es central en el espíritu empresarial social. Esta escuela tiene mucho peso en la literatura de Estados Unidos, donde las proposiciones de valor de los emprendedores sociales son tomadas como conductores del cambio social (Defourny y Nyssens, 2014).

Los motores principales de esta escuela fueron B.Drayton y Ashoka. La misión de Ashoka fue, y todavía lo es, "buscar y apoyar a personas excepcionales con un patrón de ideas ajustadas para el cambio social". Se centra en perfiles de personas muy específicas, capaces de llevar a cabo innovación social en varios campos más que en la forma de organización que pueden llevar a cabo. Aunque muchas iniciativas de emprendedores sociales se plasman en la creación de organizaciones no lucrativas, trabajos recientes muestran oportunidades para la innovación social dentro del sector privado lucrativo e incluso dentro de la esfera pública (Defourny y Nyssens, 2008).

Parece que las diferencias entre las dos escuelas americanas se van reduciendo, ya que es bastante común que, en la actualidad, las escuelas de negocio y las fundaciones fomenten métodos empresariales de manera más amplia, es decir, no solo como estrategias ganadoras de ingresos sino como un camino hacia la innovación social. La Tabla 2 recoge las principales características de las dos principales escuelas de pensamiento en Estados Unidos. 


\section{Tabla 2. Principales características de las escuelas de pensamiento de Estados Unidos en relación al concepto de empresa social}

\begin{tabular}{|c|c|c|}
\hline \multicolumn{2}{|c|}{$\begin{array}{l}\text { Escuela "Earned Income" } \\
\text { • Concepción de empresa social basada en "estrategias ganadoras de ingreso" } \\
\text { en apoyo a la misión social }\end{array}$} & \multirow{2}{*}{$\begin{array}{l}\text { Escuela de "Innovación social" } \\
\text {-Énfasis en el perfil y comporta- } \\
\text { miento de los emprendedores } \\
\text { sociales como responsables del } \\
\text { cambio social } \\
\text { - Iniciativas de los emprendedores } \\
\text { sociales plasmadas en } \\
\text { organizaciones no lucrativas y en } \\
\text { organizaciones lucrativas } \\
\text { - Naturaleza de la actividad } \\
\text { comercial en estrecha relación } \\
\text { con la misión social }\end{array}$} \\
\hline $\begin{array}{l}\text { "Commercial Non-Profit" } \\
\text { - Centrado en organizaciones } \\
\text { sin fines de lucro } \\
\text { (no reparto de beneficios) } \\
\text { - Actividades comerciales } \\
\text { consideradas como fuentes } \\
\text { de ingresos } \\
\text { - La naturaleza de la actividad } \\
\text { comercial no tiene por qué estar } \\
\text { relacionada con la misión social }\end{array}$ & $\begin{array}{l}\text { "Mission-Driven Business" } \\
\text {-Visión más amplia que } \\
\text { incluye a compañías lucrativas } \\
\text {-Empresas con propósito social }\end{array}$ & \\
\hline
\end{tabular}

FUENTE: Elaboración Propia.

\subsection{Comparando los principales enfoques de la empresa social}

Europa y Estados Unidos tienen enfoques diferentes del concepto de empresa social debido, en parte, a que su aparición en ambas regiones refleja respuestas únicas a las diferentes dificultades económicas con las que se enfrentaron en el pasado (Doeringer, 2010). En Estados Unidos, la empresa social fue una respuesta empresarial (de mercado) a cuestiones sociales, es decir, las organizaciones no lucrativas desarrollaron estrategias de obtención de ingresos ante la reducción de subsidios públicos y de donaciones privadas a las entidades no lucrativas a raíz de la crisis de los años setenta 8 . En Europa Occidental, sin embargo, el concepto de empresa social evolucionó de manera importante centrándose en resolver problemas de desempleo estructural. Las empresas sociales también surgen como una respuesta empresarial en el ámbito del mercado a una cuestión social concreta: el problema del desempleo de colectivos de difícil empleabilidad. No se crean para financiar organizaciones no lucrativas de acción social, sino para resolver un problema de desempleo desarrollando actividades productivas de cualquier índole.

8. - Una de las teorías utilizadas para explicar la emergencia de la empresa social es la Teoría de la Dependencia de Recursos, según la cual la empresa social surge como una solución racional ante la reducción de los fondos públicos a las organizaciones no lucrativas y la mayor competencia en las donaciones filantrópicas. Esta ha sido la teoría habitualmente utilizada en el caso de Estados Unidos, aunque existen algunos autores que señalan que el supuesto de disminución de donaciones públicas y privadas en el caso de las organizaciones no lucrativas en Estados Unidos, es empíricamente cuestionable (Teasdale, 2010). 
Además, aunque los debates conceptuales surgidos en los años ochenta en relación a los nuevos comportamientos empresariales (conducidos principalmente por un propósito social) tuvieron lugar dentro del Tercer Sector tanto en Europa como en Estados Unidos, en Europa la tradición cooperativa jugó un papel significativo en varios países mientras que las fundaciones fueron actores importantes en Estados Unidos. Es precisamente esa herencia cooperativa en el caso europeo la que ha generado que la estructura de gobierno de las empresas sociales haya atraído mucha más atención en Europa que en Estados Unidos, dando como resultado una mayor vinculación del emprendimiento social y las empresas sociales a la cuestión de la democracia y la participación.

Para poder adoptar una perspectiva comparada de los principales enfoques presentados en relación al concepto de empresa social, se toman como referencia los tres subconjuntos o dimensiones en los que Defourny y Nyssens presentan los diferentes criterios económicos y sociales del enfoque EMES. La Tabla 3 recoge una síntesis de las principales coincidencias y diferencias entre el enfoque europeo (EMES y británico) y el enfoque norteamericano (distinguiendo sus principales corrientes de pensamiento).

\section{Tabla 3. Principales coincidencias y diferencias entre los principales enfoques de empresa social}

\begin{tabular}{|c|c|c|c|c|}
\hline \multirow[t]{2}{*}{ Enfoque EMES } & \multicolumn{2}{|c|}{ Escuela "Earned Income" } & \multirow{2}{*}{$\begin{array}{l}\text { Escuela } \\
\text { "Innovación Social" }\end{array}$} & \multirow{2}{*}{$\begin{array}{l}\text { Enfoque } \\
\text { británico }\end{array}$} \\
\hline & "Commercial Nonprofit" & "Mission-Driven Bussines" & & \\
\hline $\begin{array}{l}\text { Dimensión económica y empresarial: } \\
\text { Naturaleza de la actividad } \\
\text { económica en estrecha relación } \\
\text { con la misión social. } \\
\text { Riesgo económico: la sostenibilidad } \\
\text { financiera descansa en un mix de } \\
\text { recursos de mercado (ingresos } \\
\text { comerciales) y no mercado } \\
\text { (subvenciones, donaciones). }\end{array}$ & \multicolumn{2}{|c|}{$\begin{array}{l}\text { Naturaleza de la actividad económica no relacionada con la } \\
\text { misión social. }\end{array}$} & $\begin{array}{l}\text { Naturaleza de la actividad } \\
\text { económica en estrecha } \\
\text { relación con la misión social. } \\
\text { Sostenibilidad basada en un } \\
\text { mix de recursos de mercado } \\
\text { y no mercado. }\end{array}$ & $\begin{array}{l}\text { Naturaleza de la actividad } \\
\text { en relación con la misión } \\
\text { social. } \\
\text { Ingresos comerciales } \\
\text { representan al menos el } \\
25 \% \text { de los ingresos totales } \\
\text { (DTI), (al menos el } 50 \% \text {, } \\
\text { SEM y SEUK). }\end{array}$ \\
\hline $\begin{array}{l}\text { Dimensión social: } \\
\text { Objetivo explícito de beneficio a la } \\
\text { comunidad o creación de valor social. } \\
\text { Dinámicas colectivas. } \\
\text { Se permite distribución limitada de } \\
\text { beneficios (organizaciones no } \\
\text { lucrativas y lucrativas). }\end{array}$ & $\begin{array}{l}\text { Garantizado por la reinversión } \\
\text { total de beneficios. } \\
\text { No se dice nada al respecto. } \\
\text { Se prohíbe la distribución de } \\
\text { beneficios (organizaciones } \\
\text { no lucrativas). }\end{array}$ & $\begin{array}{l}\text { No queda garantizado. } \\
\text { No se dice nada al respecto. } \\
\text { Se pueden distribuir } \\
\text { beneficios (organizaciones } \\
\text { lucrativas y no lucrativas). }\end{array}$ & $\begin{array}{l}\text { Si se hace explíito. } \\
\text { Primacía de iniciativas individ. } \\
\text { Se pueden distribuir benefi- } \\
\text { cios (organizaciones lucrati- } \\
\text { vas y no lucrativas). }\end{array}$ & $\begin{array}{l}\text { Sí se hace explícito en } \\
\text { documentos constitutivos. } \\
\text { No se dice nada al respecto. } \\
\text { Reinversión de al menos el } \\
50 \% \text { de beneficios (DTI, } \\
\text { SEM y SEUK). }\end{array}$ \\
\hline $\begin{array}{l}\text { Dimensión participativa: } \\
\text { Autonomía } \\
\text { Toma de decisiones democrática } \\
\text { Toma de decisiones participativa }\end{array}$ & $\begin{array}{l}\text { No se especifica, pero la auton } \\
\text { públicos parece garantizada po } \\
\text { así respecto a las organizacion } \\
\text { No es requisito. } \\
\text { No es requisito. }\end{array}$ & $\begin{array}{l}\text { omía respecto a organismos } \\
\text { r la autosuficiencia, aunque no } \\
\text { es privadas que las crean. }\end{array}$ & $\begin{array}{l}\text { No se especifica como tal, } \\
\text { pero parece que va en la } \\
\text { misma línea de EMES. } \\
\text { No es requisito. } \\
\text { No es requisito. }\end{array}$ & $\begin{array}{l}\text { Gobierno autónomo } \\
\text { Participación y control por } \\
\text { grupos de interés (DTI). } \\
\text { Controlada en interés de la } \\
\text { misión social (SEUK). }\end{array}$ \\
\hline
\end{tabular}

FUENTE: Elaboración propia.

CIRIEC-España, Revista de Economía Pública, Social y Cooperativa 
De la comparación de los tres enfoques se observan coincidencias importantes entre el enfoque EMES, el británico y la escuela de "Innovación Social" del enfoque norteamericano, si bien el enfoque británico concreta algunos criterios como el porcentaje mínimo de ingresos que debe generar la actividad de las empresas sociales y el porcentaje mínimo de reinversión de beneficios. La principal diferencia se encuentra en el criterio de gobernanza, criterio al que no hace referencia la escuela de "Innovación Social".

El amplio debate al que han dado lugar estos enfoques y en el que participan diferentes autores profesionales y organizaciones ha generado un importante desarrollo del concepto de empresa social pero sin una definición compartida. Si bien existe cierto consenso sobre la naturaleza de la empresa social, este se da a un nivel elevado de abstracción (Young y Lacy, 2012). Las definiciones actuales no consiguen explicar suficientemente los fundamentos e implicaciones prácticas de las características de la empresa social. Esta diversidad conceptual se manifiesta en las distintas definiciones y marcos legales existentes en los países de la Unión Europea, por lo que se hace necesario su examen.

\section{3.- La realidad de la empresa social en los países de la Unión Europea: marcos conceptuales, escenarios jurídicos y formas legales}

\subsection{Comisión Europea: definiciones y características de la empresa social}

Para la Comisión Europea las empresas sociales son una respuesta endógena de la sociedad a los fallos de mercado y a las deficiencias de las políticas públicas (Borzaga et al., 2013). Estas son reconocidas como elementos esenciales del crecimiento económico y la creación de empleo, reconocimiento que ha sido destacado en distintos documentos políticos e iniciativas de la Comisión Europea.

Los distintos aspectos de la definición de empresa social dados por la Comisión Europea se recogen en diferentes comunicados publicados a lo largo de los años 2011 y 2012 en relación a la "Iniciativa en favor del emprendimiento Social", ("Social Business Intiative", SBI). Esta primera noción de empresa social ha sido desarrollada y refinada en los últimos años por la literatura académica y política europea. En 2013 la Comisión publicó "Social economy and social entrepreneurship. Social Europe Guide", bajo la dirección, entre otros, de Carlo Borzaga, en la que se recogen las características más importantes de lo que se considera una empresa social en Europa en línea con la definición de la Comisión contenida en la SBI de 2011, aunque con algunas matizaciones en relación a la estructura de ingresos (se especifica que una parte sustancial de los ingresos debe venir del comercio) 0 en relación a su origen (se reconoce la posibilidad de que las empresas sociales sean creadas por un empresario social individual). 
Un estudio de la Comisión Europea de 2014, "A map of social enterprise and their eco-systems in Europe", intenta hacer la definición de empresa social más operativa de forma que permita, por un lado, distinguir las empresas sociales de las empresas convencionales y de las entidades tradicionales de la economía social y, por otro, delinear la difusión de la empresa social y su actividad entre países europeos con diferentes contextos económicos y de bienestar, tradiciones y sendas de desarrollo de las empresas sociales. Basándose en la noción de empresa social recogida en la SBI (2011) establece tres dimensiones, -la dimensión empresarial, la dimensión social y la dimensión de gobernanzaespecificadas en un conjunto de criterios básicos que delimitan el concepto de empresa social muy similares a los establecidos por el enfoque EMES.

En diciembre de 2015 el Consejo de la Unión Europea en sus conclusiones sobre "La promoción de la Economía Social como motor clave del desarrollo económico y social europeo", entiende el concepto de empresa social de la misma forma que en la SBI de 2011. La Tabla 4 recoge las definiciones y características del concepto de empresa social que la Comisión Europea ha ido presentando en los últimos años.

\section{Tabla 4. Comisión Europea: Definiciones y características de la empresas social}

\begin{tabular}{|c|c|c|c|}
\hline $\begin{array}{c}\text { Social Business } \\
\text { Initiative, SBI (CESE, 2011) }\end{array}$ & $\begin{array}{l}\text { Informe del Parlamento } \\
\text { Europeo (2012) }\end{array}$ & $\begin{array}{l}\text { Social Economy and Social } \\
\text { Entrepreneurship. Social } \\
\text { Europe Guide (2013) }\end{array}$ & $\begin{array}{c}\text { A map of social enterprise } \\
\text { and their eco-system in } \\
\text { Europe (2014) }\end{array}$ \\
\hline $\begin{array}{l}\text { La empresa social es un opera- } \\
\text { dor de la economía social cuyo } \\
\text { principal objetivo es tener un } \\
\text { impacto social más que obtener } \\
\text { beneficios para sus propietarios } \\
\text { o accionistas. Opera proporcio- } \\
\text { nando bienes y servicios para } \\
\text { el mercado, de un modo } \\
\text { empresarial e innovador y uti- } \\
\text { liza principalmente sus benefi- } \\
\text { cios para lograr objetivos } \\
\text { sociales. Está dirigida de una } \\
\text { forma responsable y abierta y, } \\
\text { en particular, implica a emplea- } \\
\text { dos, consumidores y grupos de } \\
\text { interés afectados por sus activi- } \\
\text { dades comerciales }\end{array}$ & $\begin{array}{l}\text { Su objetivo primordial es } \\
\text { conseguir un impacto social } \\
\text { positivo y medible a través de } \\
\text { la producción y provisión de } \\
\text { bienes y servicios a personas } \\
\text { vulnerables, o del empleo de } \\
\text { métodos de producción que } \\
\text { incorporen su objetivo social. } \\
\text { Utilizan sus beneficios princi- } \\
\text { palmente para la consecución } \\
\text { de sus objetivos. } \\
\text { Gestión responsable y } \\
\text { transparente, involucrando a } \\
\text { empleados, clientes e interesa- } \\
\text { dos afectados por su actividad } \\
\text { empresarial }\end{array}$ & $\begin{array}{l}\text { Propósito social. } \\
\text { Restricción a la distribución } \\
\text { de beneficios y activos. } \\
\text { Ganancia sustancial de una parte } \\
\text { de sus ingresos del comercio. } \\
\text { Mantienen un equilibrio entre la } \\
\text { dimensión económica y social. } \\
\text { Énfasis en el interés general. } \\
\text { Creadas por un empresario social } \\
\text { o por un grupo de ciudadanos que } \\
\text { comparten una meta social espe- } \\
\text { cífica y bien definida. } \\
\text { Establecen acuerdos instituciona- } \\
\text { les específicos para perseguir el } \\
\text { objetivo social, que consisten en } \\
\text { una dimensión participativa y } \\
\text { colectiva. }\end{array}$ & $\begin{array}{l}\text { Realización de una actividad } \\
\text { económica continuada con } \\
\text { un propósito social explíito y } \\
\text { prioritario. } \\
\text { Un objetivo social es aquel } \\
\text { que beneficia a la sociedad. } \\
\text { Existencia de mecanismos } \\
\text { que bloqueen los objetivos } \\
\text { sociales de la empresa: lími- } \\
\text { tes a la distribución de } \\
\text { beneficios y activos, y pro- } \\
\text { ceso de toma de decisiones } \\
\text { democrático y participativo. } \\
\text { Organizaciones indepen- } \\
\text { dientes de las organizacio- } \\
\text { nes del Estado y de otras } \\
\text { organizaciones tradicionales } \\
\text { lucrativas. }\end{array}$ \\
\hline
\end{tabular}

FUENTE: Elaboración propia.

CIRIEC-España, Revista de Economía Pública, Social y Cooperativa 
3.2. Marco conceptual, escenario legislativo y formas legales en los países de la Unión Europea

En la mayoría de países de la Unión Europea el concepto de empresa social es bastante nuevo y está poco desarrollado, prevaleciendo la mayoría de veces el concepto de economía social. Las definiciones que utilizan los países de la Unión Europea son específicas de lo que a nivel nacional se entiende por el fenómeno de la empresa social. Esto da lugar a una gran variedad de definiciones que se refleja en los diferentes escenarios legales y formas jurídicas que de forma creciente se han ido desarrollando en las últimas décadas en muchos países europeos para apoyar y promocionar la empresa social.

Nos encontramos, por tanto, a nivel europeo con distintas legislaciones, pudiéndose distinguir entre: (1) Legislaciones generales sobre empresa social o entidades similares, que permiten la calificación de empresa social a todas las entidades que se ajusten a determinados criterios y, (2) Legislaciones específicas, centradas en formas jurídicas precisas. (Borzaga y Nogales, 2013; Borzaga et al., 2013).

\section{Figura 1. Legislaciones generales y específicas}

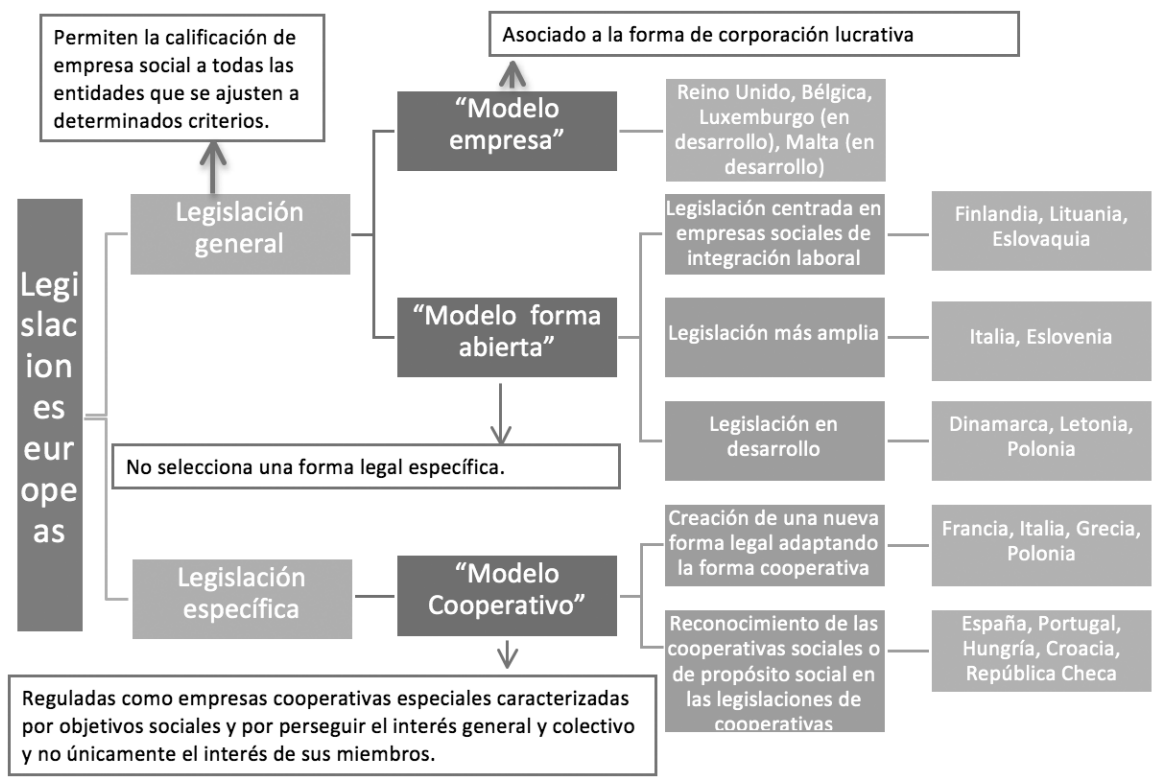

FUENTE: Elaboración propia a partir de Borzaga y Nogales, 2013; Borzaga et al., 2013; Cafaggi y lamiceli, 2008. 
Del análisis de las distintas legislaciones generales y específicas se desprenden las siguientes cuestiones: (i) En todas las legislaciones se requiere que las empresas sociales lleven a cabo una actividad regular y continuada de producción de bienes o servicios con un objetivo social explícito y prioritario; (ii) el objetivo social se deriva de la utilidad social, el interés general o el beneficio público de los bienes producidos o de los servicios prestados, o del empleo de grupos desfavorecidos en el proceso de producción o distribución; (iii) en la totalidad de las legislaciones se reconoce que una parte importante de los ingresos debe proceder de la actividad comercial, estableciendo tres legislaciones criterios concretos de ingresos mínimos: Malta el $75 \%$, Italia el 70\%, y Eslovenia el $40 \%$ tras el segundo año de existencia y el 50\% a partir del tercero; (iv) en relación a la distribución de beneficios dos legislaciones generales no establecen ningún tipo de restricción (Finlandia y Lituania), en tres se prohíbe totalmente la distribución de beneficios (Italia, Polonia e Italia), y en siete se permite una distribución limitada, fijándose criterios mínimos de reinversión en 2 de estas legislaciones (Eslovaquia el $30 \%$ y Eslovenia el $80 \%$ ). En las legislaciones del modelo cooperativo, solo se permite la distribución limitada en cuatro de las diez legislaciones; (v) En siete de las doce legislaciones generales se contempla el bloqueo de activos y en seis de las diez legislaciones específicas; (vi) Por último, por lo que respecta a la gobernanza, cuatro legislaciones generales recogen el carácter democrático que debe estar presente en la toma de decisiones de las empresas sociales (Malta, Letonia, Eslovenia y Polonia). La implicación de grupos de interés en el proceso de toma de decisiones se recoge en cuatro de las legislaciones generales (Reino Unido, Italia, Eslovenia y Dinamarca), y tres legislaciones no establecen requisito alguno de gobernanza (Finlandia, Lituania y Eslovaquia). En las 10 legislaciones del modelo cooperativo se requiere gobernanza democrática y en tres, además, participativa (Francia, Grecia y Portugal).

\section{4.- Características identitarias de la empresa social en Europa}

El análisis de los distintos enfoques y corrientes de pensamiento junto con el examen de la realidad conceptual y normativa de la empresa social en Europa ha constituido la base teórica para la propuesta del conjunto de características identitarias de la empresa social. Este conjunto de criterios tiene un carácter general. Su concreción y cuantificación dependerá tanto del contexto (histórico, cultural, económico, institucional...) en el que se desarrolle la empresa social (Kerlin, 2013), como de factores específicos de las empresas sociales (tamaño, madurez, origen...), dando lugar a distintos modelos o tipologías de empresas sociales. 


\section{Figura 2. Carcaterísticas identitarias básicas de la empresa social}

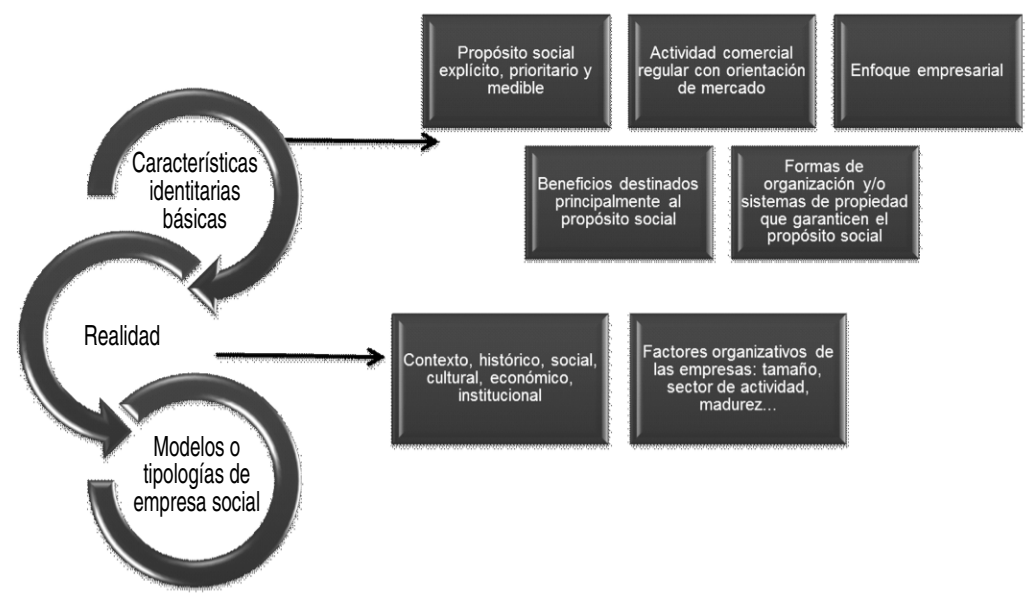

\subsection{Organizaciones privadas con propósito social explícito prioritario y medible}

La palabra "social" ha sido utilizada en el ámbito de la literatura de la iniciativa empresarial social, empresa social y organizaciones no lucrativas para describir cosas muy diferentes, como motivaciones o intenciones sociales, sector social como categoría jurídica, problemas sociales o impacto social, (Phills et al., 2008). Parece que las definiciones de "social" más adecuadas son aquellas centradas en la descripción de una clase de necesidades o problemas, ya que suele existir un mayor consenso dentro de las sociedades sobre lo que constituye una necesidad o problema social y sobre la clase de objetivos sociales que tienen valor (justicia, equidad, preservación del medio ambiente, mejoras en la salud, arte, cultura y mejor educación...) y que se pueden acumular tanto en segmentos desfavorecidos de la población como en la sociedad en su conjunto.

Los problemas o necesidades sociales pueden diferir de una sociedad a otra. Por tanto, como señala Yunus, para poder hablar de valor social es necesario precisar, en primer lugar, lo que se entiende por problema social en un contexto o sociedad determinado. En este sentido, una empresa social se crea con el propósito social de afrontar un problema o necesidad social, si bien el problema o necesidad a resolver dependerá del contexto en el que se desarrolle la empresa ${ }^{9}$.

9.- En las legislaciones europeas de empresa social encontramos diferentes propósitos sociales. En algunas el propósito social se centra en la integración laboral y social de grupos vulnerables (Finlandia, Lituania, Eslovaquia), en otros en la mejora del bienestar y de las condiciones de vida de un sector de la sociedad (CICs, Italia, Eslovenia)... 


\section{IDENTIFICACIÓN Y ANÁLISIS DE LAS CARACTERÍSTICAS IDENTITARIAS DE LA EMPRESA SOCIAL EUROPEA: APLICACIÓN A LA REALIDAD DE LOS CENTROS ESPECIALES DE EMPLEO DE LA ECONOMÍA ESPAÑOLA}

Otra forma en la que se suele utilizar la palabra "social" es para describir una clase de valor distinto del valor financiero o económico. Aunque todas las empresas tienen una misma finalidad (crear valor y maximizar sus resultados) el valor y los resultados pueden ser diferentes según el tipo de empresa y según los objetivos perseguidos por quienes las controlan o se benefician de sus actividades $^{10}$. En ocasiones se crea valor económico y, por tanto, se busca la maximización de la rentabilidad del capital invertido por los socios o accionistas. En otros casos, se pretende crear valor social y se busca la maximización del impacto social. Tradicionalmente se piensa que el valor económico es el creado por las empresas capitalistas y el valor social es el creado por las organizaciones sin fines de lucro o gubernamentales. Sin embargo, las empresas sociales pretenden crear valor económico y valor social, buscando maximizar el impacto o beneficio social.

Es importante señalar que existe una diferencia entre la maximización del beneficio (propio de las empresas lucrativas tradicionales) y la obtención de beneficio (propio de las empresas sociales). Es precisamente la primacía del objetivo social más allá de los objetivos económico-financieros una de las diferencias básicas de las empresas sociales respecto a las empresas lucrativas, que buscan la maximización del beneficio para la ganancia de los inversores de capital ${ }^{11}$. Por tanto, las empresas sociales se diferencian de las empresas lucrativas tradicionales en la centralidad de su misión social (Doerthy et al., 2014).

En definitiva, las empresas sociales "no compiten para ser las mejores del mundo, sino para ser las mejores para el mundo... La gran ventaja de este tipo de empresas es que, sin renunciar a funcionar como empresas -lo que significa ser eficientes y tener utilidades- no olvidan que tienen un objetivo primario relacionado con el bien común". (Lema de las B Corps.) ${ }^{12}$

Esta primera característica identitaria permite diferenciar a las empresas sociales de las empresas lucrativas tradicionales ya que la finalidad social de las primeras es fundamental para lo que hacen. Así, no se consideran empresas sociales aquellas empresas lucrativas que generan un impacto social indirecto a través de la práctica de la Responsabilidad Social Corporativa (RSC), es decir, creando fundaciones filantrópicas, utilizando materias primas respetuosas con el medio ambiente, proporcionando voluntarios para ayudar en proyectos comunitarios, participando en actividades beneficiosas como donaciones, patrocinio ${ }^{13}$... La Comisión Europea también se manifiesta en este mismo sentido al señalar que el concepto de Responsabilidad Social de las Empresas (RSE) debe distinguirse del concepto de Economía Social y del de empresa social. El reconocimiento de la empresa social a nivel de la

10.- Dictamen del CESE sobre "Distintos tipos de empresas", 2009.

11.- Esa primacía de los objetivos sociales se refleja en algunas legislaciones. Por ejemplo, la legislación belga que regula las Sociedades de Finalidad Social obliga a que los estatutos de dichas sociedades estipulen que sus miembros buscan poca o ninguna rentabilidad de su inversión.

12.- $h$ ttp://www.innovacion.gob.cl/reportaje/las-nuevas-companias-del-siglo-xxi/

13.- Galera y Borzaga (2009), no consideran como empresas sociales a aquellas empresas lucrativas que participan en proyectos o iniciativas sociales. 
UE no debe limitarse a incluir objetivos sociales en determinadas empresas comerciales sino que debe tener en cuenta la naturaleza específica de las empresas sociales (SBI, 2011).

Además, las empresas sociales están más orientadas que otras organizaciones de la Economía Social a hacer frente, no solo a las necesidades de sus propietarios o miembros, sino también a las necesidades de una comunidad más amplia ${ }^{14}$. Esta marcada orientación hacia el interés general del propósito social permite diferenciar a las empresas sociales de otras organizaciones de la economía social que, aunque poseen un indudable valor añadido social, están más orientadas a la satisfacción de las necesidades de sus propietarios o miembros.

4.2. Actividad económica continuada y regular con orientación de mercado: producción y venta de bienes y servicios a precios económicamente significativos

El propósito social de las empresas sociales puede resultar tanto de la naturaleza de los bienes y servicios suministrados -por ejemplo, servicios sociales relacionados con necesidades de la comunidad (como educación o salud)- como del proceso de producción y/o distribución (integración laboral, comercio justo, energía verde...) o a través de la combinación de esas dos dimensiones. Es decir, las empresas sociales hacen frente de forma directa a necesidades sociales o lo que es lo mismo, persiguen su propósito social mediante la producción y venta de bienes o servicios, o mediante el número de personas desfavorecidas o métodos de producción que emplean.

Dado que la finalidad o propósito social puede referirse a campos muy diferentes, las empresas sociales pueden estar activas en un amplio espectro de actividades (Defourny y Nyssens, 2014; Heckl, 2007; Jhonson y Spear, 2006): (i) Formación e integración en el empleo de personas excluidas del mercado de trabajo o de grupos vulnerables. Este es el caso de las "Empresas sociales de integración laboral" (WISE; Work Integration Social Enterprise) cuyo objetivo es ayudar a la población en riesgo de exclusión permanente (discapacitados, desempleados de larga duración, minorías...) a integrarse en el mundo laboral y en la sociedad a través de la actividad productiva; (ii) Prestación de servicios sociales. Las empresas sociales pueden operar en la prestación de servicios de bienestar a grupos específicos de individuos -o dentro de una comunidad específicamente definida- en áreas de atención sanitaria y social principalmente, aunque la expansión de los servicios puede ser muy amplia.; (iii) Prestación de servicios personales diversos, cuidado de niños, ayuda a personas discapacitadas, servicios personales a la tercera edad, servicios de atención domiciliaria... Aquí estarían incluidos los llamados "servicios de proximidad" que hacen referencia a una variedad de servicios personales o colectivos; (iv) Desarrollo local de áreas desfavorecidas (urbanas/rurales); (v) Otros campos de actividad, otros servicios de interés más general para las comunidades locales

14.- El concepto de comunidad puede tener un amplio rango de significados, desde la población como un todo a una sección de la comunidad, los residentes de un área particular o un grupo de personas con una desventaja concreta y particular. 
como protección medioambiental y del ecosistema, patrimonio cultural y servicios culturales, turismo social, actividades de investigación y educación...

La realización de una actividad continuada de producción y venta de bienes y/o servicios a precios económicamente significativos conduce a no considerar empresas sociales a aquellas organizaciones del Tercer Sector o de la Economía Social cuya actividad principal no consiste en el desarrollo de actividades empresariales, -y que realizan principalmente funciones de promoción o redistribución de flujos financieros como actividad principal-, o que prestan servicios u ofrecen bienes con objetivos sociales pero a precios no económicamente significativos. Además, la relación entre la actividad comercial y el propósito social lleva a no considera como empresas sociales a aquellas empresas lucrativas que producen bienes y servicios que no son socialmente relevantes, ni por su naturaleza ni por el proceso de producción o distribución utilizado aunque utilicen sus beneficios o parte de ellos para la consecución de objetivos sociales. Esto sería el caso de las subsidiarias comerciales de organizaciones benéficas.

\subsection{Actividad económica realizada con enfoque empresarial}

Una empresa social opera con una cantidad mínima de trabajo remunerado aunque también puede contar con voluntarios en sus actividades. La realización de una actividad económica continua y regular exige contar con una plantilla de trabajadores contratados estable.

Además, las empresas sociales deben asumir el riesgo económico inherente a la iniciativa, es decir, la viabilidad financiera de la empresa depende de los esfuerzos de los miembros y trabajadores para asegurar los recursos financieros adecuados. Dichos recursos pueden estar formados por una mezcla de recursos propios y ajenos, entre los cuales los ingresos obtenidos de la actividad comercial representan una parte significativa. La cuantía que deben representar esos ingresos para que una organización sea considerada empresa social puede ir desde mínimos a una total dependencia del ingreso comercial (Doerthy et al., 2014).

Resulta complicado establecer un criterio general en relación a cuál debe ser el umbral de ingresos comerciales para que una empresa sea considerada empresa social. Salamon et al. (2004), en un estudio sobre empresas sociales realizado en 34 países, encontraron que la prevalencia de ingresos comerciales era más frecuente en aquellos países con sectores de la sociedad civil más pequeños, con pocos recursos del sector público y filantrópico, sugiriendo que el contexto particular de cada país 0 región influye en las características de las empresas sociales. Del mismo modo, Thesis y Vencheva (2012), señalan que las empresas sociales tienen estructuras financieras diferentes en distintos países debido a que las regulaciones institucionales de cada país afectan a la extensión en la cual las empresas sociales pueden acceder a distintos recursos. Además, señalan que incluso dentro de un mismo país o región se pueden observar diferencias en las estructuras financieras de las empresas sociales dependiendo de la etapa de desarrollo en la que se encuentre la empresa. 
En definitiva, y sin perjuicio de que el umbral de ingresos comerciales mínimo de las empresas sociales mantenga una cierta flexibilidad en los primeros años de su recorrido y en función del contexto económico, político y social en el que se desarrolle la empresa, lo que resulta claro de cuanto se ha dicho es que las empresas sociales son productoras de mercado, a diferencia de otras organizaciones de acción social (tercer sector de acción social), que son productoras de no mercado y que la Contabilidad Nacional incluye en el sector institucional "Instituciones sin fines de lucro al servicio de los hogares" (ISFLSH).

El hecho de que las empresas sociales descansen de manera significativa en los ingresos obtenidos de su actividad comercial contribuye a su autonomía. Las empresas sociales deben ser propiedad y estar controladas en interés de su propósito social. De este modo, la Comisión Europea señala que las empresas sociales deben ser autónomas respecto al Estado y a otras organizaciones tradicionales lucrativas ${ }^{15}$, recogiéndose también esta característica o requisito en algunas legislaciones ${ }^{16}$.

\subsection{Utilización prioritaria de los beneficios para el cumplimiento del propósito social}

Las empresas sociales no tienen por qué ser organizaciones no lucrativas ya que pueden distribuir parte de sus beneficios. Una empresa social puede elegir deliberadamente la forma lucrativa y no buscar la maximización del beneficio como objetivo prioritario. El lucro per se no es un problema para las empresas sociales ya que las ganancias son deseables siempre y cuando se encaucen hacia el logro del propósito social de la empresa. Lo que caracteriza a las empresas sociales y las distingue de las empresas lucrativas tradicionales es la forma en la que utilizan los beneficios que generan a través de su actividad comercial.

Uno de los puntos de discrepancia en torno al concepto de empresa social es, precisamente, el relacionado con la distribución de beneficios. Por un lado existe el discurso "not-for profit" que defiende que las empresas sociales no deben distribuir sus beneficios, alentando así altos niveles de reinversión que garantizan el cumplimiento de la misión social. Por otro lado, están los que piensan que la reinversión de parte de los beneficios, junto con otras características, puede ser un indicador de que la empresa no se establece principalmente para generar valor económico para los propietarios 0 accionistas, si bien permitir que una parte de los beneficios puedan ser distribuidos puede facilitar la obtención de financiación distinta a las subvenciones gubernamentales y donaciones privadas.

La reinversión de parte de los beneficios obtenidos se considera una característica identitaria de la empresa social, que junto con otras características permite garantizar la primacía del propósito social. Sin embargo, el porcentaje de reinversión mínimo para que una empresa pueda ser considerada empresa social no está establecido con carácter general. Las legislaciones y definiciones nacio-

15.- European Commission, 2014.

16.- Ley de Empresa Social italiana, ley eslovena, Dinamarca... 
nales de los países de la Unión Europea plantean un umbral mínimo de reinversión de beneficios que oscila entre el $20 \%$ y el $50 \% 17$.

\subsection{Adopción de formas de organización o sistemas de propiedad que reflejen el propósito social}

Para Defourny y Nyssens (2008), la estructura de gobierno de una empresa social es un conjunto de dispositivos organizativos que aseguran que se persigue la misión social de la empresa. Por su parte, Mason (2009) define la gobernanza de las empresas sociales como el liderazgo estratégico y operativo que permite a los usuarios, directores y otros grupos de interés crear y maximizar el beneficio social. Precisamente es la maximización del beneficio social lo que hace difícil encontrar estructuras de gobernanza apropiadas que gestionen los riesgos empresariales sosteniendo a la vez sus valores fundamentales. La doble misión de la empresa social, económica y social, significa que diferentes grupos de interés tienen reclamaciones de desempeño distintas, lo que aumenta la complejidad de las estructuras de gobernanza apropiadas (Doerthy et al., 2014).

Diversas investigaciones ponen de manifiesto que no hay una estructura de gobierno única que se adapte a todas las empresas sociales o incluso que se ajuste a la misma empresa a lo largo del tiempo, sino que existe una amplia variedad de estructuras de gobernanza con diferentes niveles de formalización, tamaño del consejo, composición... (Spear et al. 2009; Schöning et al. 2012). Factores organizativos específicos de las empresas sociales como tamaño de la empresa, grado de complejidad o madurez, recursos financieros principales, orígenes y patrón de desarrollo de la empresa..., conducen a consideraciones específicas que las empresas sociales deben abordar con una gobernanza adecuada (Schöning et al. 2012; Huybrechts et al. 2014; Spear et al. 2009).

No obstante lo anterior, deberían establecerse criterios generales para que la gobernanza de las empresas sociales permita reflejar y garantizar el propósito social. Así la gobernanza debería incluir principios democráticos y participativos, que representen y garanticen la prioridad y cumplimiento del propósito social, que pueden combinarse con elementos propios de la gobernanza de las empresas lucrativas tradicionales, que representen y gestionen la parte empresarial o de negocio. Sin embargo, es preciso reconocer que en determinadas empresas sociales la aplicación de principios democráticos y participativos, consustanciales a las mismas, debe entenderse de forma flexible en consideración a las características especiales de los colectivos participantes.

Para identificar si una organización reúne el conjunto de características identitarias básicas y, por tanto, puede ser considerada como empresa social, se requiere establecer un conjunto de indicadores. En la Tabla 5 se recogen dichos indicadores.

17.- La ley eslovena permite una distribución de beneficios del $20 \%$, mientras que en Eslovaquia se deben reinvertir al menos el $30 \%$ de los beneficios. En los requisitos establecidos por la Social Enterprise Mark en Reino Unido se establece la reinversión de al menos el $50 \%$ de los beneficios. 


\section{Tabla 5. Indicadores de las características identitarias de la empresa social}

\begin{tabular}{|c|c|c|c|c|}
\hline $\begin{array}{l}\text { 1. Propósito Social explíito, } \\
\text { prioritario y medible }\end{array}$ & $\begin{array}{l}\text { 2. Actividad económica } \\
\text { con orientación de mercado }\end{array}$ & $\begin{array}{l}\text { 3. Actividad económica } \\
\text { con enfoque empresarial }\end{array}$ & $\begin{array}{l}\text { 4. Utilización de los } \\
\text { beneficios }\end{array}$ & $\begin{array}{l}\text { 5. Organización y Propiedad } \\
\text { (gobernanza) }\end{array}$ \\
\hline $\begin{array}{l}\text { La misión, visión y valores, } \\
\text { así como los estatutos de la } \\
\text { empresa pueden ser la fuente } \\
\text { de información de: } \\
\text { - el problema o necesidad } \\
\text { social que se pretende } \\
\text { afrontar } \\
\text { - la población objetivo } \\
\text { - el ámbito geográfico } \\
\text { - los objetivos económicos } \\
\text { secundarios } \\
\text { Los márgenes de operación } \\
\text { permiten deducir si la empresa } \\
\text { está más o menos orientada } \\
\text { hacia la maximización del } \\
\text { beneficio. }\end{array}$ & $\begin{array}{l}\text { Actividad principal } \\
\text { Sector de actividad } \\
\text { Relación de bienes y } \\
\text { servicios producidos y } \\
\text { vendidos } \\
\text { Método de producción y } \\
\text { distribución utilizado } \\
\text { Precio de venta de los } \\
\text { bienes y servicios } \\
\text { Cifra de negocio }\end{array}$ & $\begin{array}{l}\text { Trabajadores empleados: } \\
\text { - № y porcentaje trabaja- } \\
\text { dores remunerados } \\
\text { - } N^{0} \text { y porcentaje de } \\
\text { voluntarios } \\
\text { Volumen de ingresos: } \\
\text { - Ingresos por ventas de } \\
\text { bienes y servicios (\% sobre } \\
\text { el total) al sector privado } \\
\text { (otras empresas y familias) } \\
\text { - Ingresos por ventas de } \\
\text { bienes y servicios (\% sobre } \\
\text { el total) al gobierno y otras } \\
\text { instituciones públicas } \\
\text { - Ingresos por ayudas: } \\
\text { subvenciones, donaciones, } \\
\text { ayudas y similares (\% } \\
\text { sobre el total) }\end{array}$ & $\begin{array}{l}\text { Volumen de beneficios } \\
\text { obtenidos } \\
\text { - Volumen y \% de } \\
\text { beneficios reinvertidos } \\
\text { - Volumen y \% de } \\
\text { beneficios distribuidos. } \\
\text { Criterios de distribu- } \\
\text { ción de beneficios: } \\
\text { a quién se } \\
\text { distribuyen y en qué } \\
\text { cuantía. }\end{array}$ & $\begin{array}{l}\text { Forma juríica } \\
\text { Número de miembros por categorías } \\
\text { Propósito del máximo órgano de gobierno (prioridad } \\
\text { propósito social sobre generación de riqueza): } \\
\text { - Decisiones tomadas, resoluciones y medidas que } \\
\text { recojan dicho compromiso } \\
\text { Máximo órgano de Gobierno } \\
\text { - Denominación y estructura del máximo órgano de } \\
\text { gobierno, incluyendo miembros y profesiones } \\
\text { - Relaciones de los miembros con la entidad, equipo } \\
\text { directivo y otros grupos de interés } \\
\text { - Retribuciones de los miembros, indicando si } \\
\text { existen límites y restricciones } \\
\text { - Medidas, procedimientos de elección } \\
\text { - \% de personas o grupos con derecho de voto con } \\
\text { respecto al total de personas de la entidad } \\
\text { - Participación real de personas con derecho de voto } \\
\text { en las reuniones celebradas } \\
\text { - Participación real de personas o grupos sin } \\
\text { derecho de voto en las reuniones celebradas. } \\
\text { Grupos de interés } \\
\text { - Número de personas o grupos, no miembros, perte- } \\
\text { necientes a grupos de interés que participan de forma } \\
\text { regular en la toma de decisiones } \\
\text { - Mecanismos de participación y número de veces al } \\
\text { año en la que se utilizan dichos mecanismos } \\
\text { - Resoluciones, compromisos que demuestren que } \\
\text { las consideraciones y propuestas de los grupos de } \\
\text { interés se han tenido en cuenta en el proceso de toma } \\
\text { de decisiones. }\end{array}$ \\
\hline
\end{tabular}

FUENTE: Elaboración propia. 


\section{5.- Aplicación de las características identitarias a los Centros Especiales de Empleo (CEE) de la economía española}

Uno de los ámbitos de actividad de las empresas sociales es el de la formación e integración en el empleo de personas excluidas del mercado de trabajo o de grupos vulnerables. Se trata de combinar formación y desarrollo de habilidades a través del empleo permanente o temporal en empresas con dimensión social que negocian en el mercado. En la Unión Europea existen unas 40 clases de organizaciones de utilidad social que buscan promover la integración de personas con dificultad a través de la actividad empresarial. Para referirse a este tipo de iniciativas de integración laboral dentro de la Economía Social, ha surgido en Europa un término específico, Work Integration Social Enterprises, WISE, (Empresas Sociales de Integración Laboral). En España, los Centros Especiales de Empleo (CEE) y las Empresas de Inserción son los ejemplos principales de WISEs (Socias y Horrach, 2012; O’Connor y Meinhard, 2014).

Los CEE son productores de mercado que pueden adoptar toda clase de formas jurídicas, societarias, asociativas o corporativas o inclusive pueden no tener forma jurídica determinada. En función de sus objetivos principales y de su titularidad el estudio realizado por CIRIEC-España18 los clasifica en CEE de la Economía Social, CEE de la Economía Pública y CEE de la Economía Capitalista.

\section{Tabla 6. Tipología CEE19}

\begin{tabular}{|lcc|}
\hline CENTROS ESPECIALES DE EMPLEO (CEE) & Objetivo Principal & Titularidad \\
\hline CEE de la Economía Social & Obtención de un impacto social & Privada \\
\hline CEE de la Economía Pública & Obtención de un impacto social & Pública \\
\hline CEE de la Economía Capitalista & Obtención de beneficios para & Privada \\
- Con personalidad jurídica & sus propietarios o accionistas & \\
- Sin personalidad jurídica (personas físicas) & & \\
\hline
\end{tabular}

FUENTE: Monzón et al., 2014.

En el citado informe se identifican un total de 2.104 CEE en España en el año 2012, de los cuales 1.058 , es decir, un $52,5 \%$ pertenecen a la Economía Social de conformidad con los criterios internacionales homologados y con la ley 5/2011 de Economía Social. La forma jurídica predominante entre los CEE de la Economía Social es el de sociedad limitada (39,3\%), seguido de asociaciones y fundaciones (que representan en conjunto el 30\%), sociedades anónimas (12,3\%), cooperativas $(9,7 \%)$ y sociedades laborales (3,5\%).

18.- Monzón et al (2014).

19.- Criterios y terminología homologados internacionalmente por la CE, el CESE, Ley 5/2011 de Economía Social, Sistema de Cuentas de la CE (SEC-2010). 
Ni los CEE de la Economía Pública, por ser de titularidad pública, ni los CEE de la Economía Capitalista, por no pertenecer a la Economía Social, pueden ser considerados empresas sociales, por los que nos centramos en los CEE de la Economía Social.

5.1. Característica 1: Son organizaciones privadas con propósito social explícito prioritario y medible

Los Centros Especiales de Empleo de la Economía Social, (CEE de la ES), son aquellos CEE de titularidad privada cuyo principal objetivo es tener un impacto social. Su propósito social explícito de interés general es proporcionar a las personas con alguna discapacidad un trabajo productivo y remunerado que facilite su integración en el mercado de trabajo ordinario (art. 42, Ley 13/1982)20. Aunque la finalidad o propósito social es el mismo en todos los CEE, dicho propósito social es prioritario en los centros de la ES. Sus ratios de rentabilidad sobre patrimonio neto y sobre fondos propios son muy inferiores a los de los CEE de la Economía Capitalista, pudiendo ser un indicador de que la rentabilidad financiera no es un objetivo en sí mismo sino que está supeditada a la finalidad social.

\section{Cuadro 1. Ratios de rentabilidad de los CEE de la Economía Social y los CEE de la Economía Capitalista, 2012}

\begin{tabular}{|l|cc|}
\hline & CEE de la Economía Social & CEE de la Economía Capitalista \\
\hline Rentabilidad sobre el patrimonio neto & 1,71 & 12,13 \\
Rentabilidad sobre fondos propios & 2,40 & 13,75 \\
\hline
\end{tabular}

FUENTE: Monzón et al., 2014.

5.2. Característica 2: Su actividad económica es continuada y con orientación de mercado

LOS CEE de la ES realizan una actividad económica continuada con orientación de mercado. Su objetivo principal es realizar un trabajo productivo, participando regularmente en las operaciones de mercado (art. 42 Ley 13/1982), por lo que su actividad principal se desenvuelve en el mercado de bienes y servicios. Pertenecen al ámbito de la "Formación e integración en el empleo de grupos vulnerables", dedicándose en un $55.4 \%$ a actividades del sector servicios, el $19 \%$ a actividades del sector industrial y el $11.4 \%$ a actividades de comercio. 
Su actividad está directamente relacionada con su propósito social por el modo en el que llevan a cabo su producción. Los CEE en general no se caracterizan por lo que producen, -su actividad puede incluir bienes y servicios que no sean sociales-, sino por la forma en la que lo hacen: empleando a personas con discapacidad.

\subsection{Característica 3: Su actividad económica se realiza con enfoque empresarial}

Los CEE de la ES realizan su actividad utilizando trabajo remunerado. No hay ningún CEE de la $E S$, ni de la economía capitalista, que opere sobre la base de trabajo voluntario. El empleo generado en los $C E E$ reúne las mismas características que el empleo generado en las empresas ordinarias, aunque los $C E E$ deben ofrecer una serie de apoyos que faciliten la integración laboral de los trabajadores con discapacidad.

Los CEE de la $\mathrm{ES}$ asumen el riesgo económico obteniendo una mezcla de recursos adecuada para llevar a cabo su actividad. Estos recursos financieros tienen un carácter híbrido y provienen del desarrollo de su actividad, de las aportaciones de los titulares de los CEE en forma de acciones, participaciones o cualquier otra forma de aportación en función del tipo de sociedad en la que se haya constituido el centro, y de recursos ajenos (créditos, subvenciones y ayudas públicas...).

\section{Cuadro 2. Estructura financiera de los CEE de la economía social y de la economía capitalista a $31 / 12 / 2012$}

\begin{tabular}{|l|cc|cc|}
\hline & \multicolumn{2}{|c|}{ CEE de la Economía Social } & \multicolumn{2}{c|}{ CEE de la Economía Capitalista } \\
& Millones de euros & $\%$ & Millones de euros & $\%$ \\
\hline TOTAL PATRIMONIO NETO+PASIVO & $2.538,5$ & 100 & $1.060,9$ & 100 \\
Reservas (autofinanciación) & 320,4 & 12,6 & 210,4 & 19,8 \\
Capital & 691,4 & 27,2 & 75,8 & 7,1 \\
Total Fondos Propios & $1.126,3$ & 44,4 & 306,0 & $\mathbf{2 8 , 8}$ \\
Subv., donaciones y legados & 447,1 & 17,6 & 41,1 & 3,87 \\
Total Patrimonio Neto & $1.576,3$ & 62,0 & 346,9 & 32,7 \\
Pasivo no corriente & 413,5 & 16,3 & 144,5 & 13,6 \\
Pasivo corriente & 548,7 & 21,6 & 569,5 & 53,7 \\
Total Pasivo & 962,2 & 37,9 & 714,0 & 67,3 \\
\hline
\end{tabular}

FUENTE: Elaboración propia a partir de Monzón et al (2014). 


\section{Cuadro 3. Estructura de los ingresos de los CEE de la economía social y de la economía capitalista a $31 / 12 / 2012$}

\begin{tabular}{|l|cc|cc|}
\hline & \multicolumn{2}{|c|}{ CEE de la Economía Social } & \multicolumn{2}{c|}{ CEE de la Economía Capitalista } \\
& Millones euros & $\%$ & Millones euros & $\%$ \\
\hline Importe neto de la cifra de negocios & $1.236,8$ & 68,62 & $2.337,1$ & 94,14 \\
Otros ingresos de explotación & 511 & 28,35 & 127,8 & 5,15 \\
Otros ingresos imputables & 54,5 & 3,02 & 17,6 & 0,71 \\
• Subvenciones de capital aplicadas a su finalidad & 32,0 & 1,77 & 6,7 & 0,27 \\
• Otros & 22,5 & 1,25 & 10,9 & 0,44 \\
Total Ingresos & $1.802,3$ & 100 & $2.482,5$ & 100 \\
\hline
\end{tabular}

FUENTE: Elaboración propia a partir de Monzón et al (2014).

La estructura financiera de los CEE de la ES (Cuadro 2) muestra que el $44 \%$ de sus recursos proviene de Fondos Propios ${ }^{21}$, el $17.6 \%$ de subvenciones, donaciones y legados, y el $37.9 \%$ de deudas a corto y largo plazo. Además, los CEE de la ES son productores de mercado, según los criterios de la Contabilidad Nacional, ya que el $68 \%$ de sus ingresos proceden de sus ventas (Cuadro 3$)^{22}$.

5.4. Característica 4: Utilizan de forma prioritaria sus beneficios para el cumplimiento del propósito social

Aunque los CEE pueden carecer o no de ánimo de lucro (art. 5/b RD 2273/1985 del Reglamento de los CEE23), los CEE de la ES identificados por las investigaciones del CIRIEC- España verifican los criterios identitarios de la Economía Social, entre ellos el destino prioritario de los beneficios al propósito social.

\subsection{Característica 5: Adoptan formas de organización que garantizan el propósito social}

Llevar a cabo una gobernanza democrática y participativa en los CEE puede resultar muy complicado debido a la naturaleza de la población objetivo de dichos centros. En algunos casos, ciertas discapacidades de las personas implicadas en los procesos de integración hacen que los principios democráticos y participativos, presentados a menudo en la economía social, sean difíciles de llevar

21.- Algunas de las ventajas de disponer de un importante volumen de fondos propios es la mayor garantía frente a terceros, la no existencia de restricciones ni obligaciones de amortización sobre esos recursos y, además, que los inversores externos a la organización no ejercen ningún control sobre dichos recursos.

22.- Sería interesante conocer el volumen y porcentaje de ventas realizadas al sector privado (otras empresas y familias) y al gobierno.

23.- Real Decreto 2273/1985 (BOE 9-12-1985) 
a cabo. Sin embargo, en muchas ocasiones son las familias de las personas con discapacidad o las organizaciones que representan a estos colectivos los que están presentes en los órganos de decisión de los centros especiales de empleo, permitiendo así su participación en la toma de decisiones.

No obstante, el cumplimiento del propósito social está garantizado en los CEE. El artículo 2 del Real Decreto 2273/85 -por el que se aprueba el Reglamento de los CEE- señala que la estructura y organización de los CEE debe salvaguardar su función social. Además hay que tener en cuenta que los CEE están sujetos a control y supervisión por parte del Ministerio de Trabajo y Seguridad Social al recibir ayudas y subvenciones que están ligadas al cumplimiento de su propósito social, por lo que cualquier desvío de su propósito principal (el empleo de personas con discapacidad) conllevaría no sólo la pérdida de dichas subvenciones y ayudas, sino también la pérdida de su calificación como CEE.

\section{6.- Conclusiones}

A pesar de la creciente visibilidad política de las empresas de la Economía Social en su conjunto $y$, en especial, de las nuevas formas de empresa social, y de su reconocimiento como pilares importantes en términos de empleo y cohesión social, sigue sin existir en la actualidad un acuerdo en el ámbito científico sobre sus características identitarias. Este trabajo ha establecido, a partir de la revisión y análisis de la literatura académica así como del marco conceptual y legislativo en los países de la UE, un conjunto de características identitarias básicas que permiten la delimitación e identificación de la empresa social en el ámbito europeo. La empresa social europea es un operador de la Economía Social que verifica sus principios y que desenvuelve su actividad empresarial en el mercado, del que proviene su principal fuente de recursos.

La conjunción de las características identitarias básicas permite, además, excluir a otras formas de organización del concepto de empresa social. Las empresas sociales se diferencian de las empresas lucrativas tradicionales porque maximizan el valor social y no el económico, porque destinan de forma prioritaria sus beneficios al propósito social y no al enriquecimiento de sus miembros y accionistas, porque generan con su actividad un impacto social directo y, porque adoptan principios democráticos y participativos en su gobernanza. Además, se diferencian de (i) las organizaciones del Tercer Sector de Acción Social, cuya actividad principal no consiste en el desarrollo de una actividad comercial y, además, se financian de donaciones, cuotas de socios y otros recursos no mercantiles; (ii) de las subsidiarias comerciales de organizaciones benéficas en las que no existe una relación directa entre la actividad comercial y el propósito social; (iii) de la mayor parte de productores de mercado de la Economía Social, cuyo propósito social está más orientado a la satisfacción de las necesidades de sus miembros que al interés general. 
Aunque el avance realizado en los últimos años en torno al concepto de empresa social ha sido muy significativo, es necesario seguir trabajando para llegar a un consenso sobre lo que son y lo que no son las empresa sociales, de forma que se puedan identificar distintas tipologías o perfiles de empresa sociales en cada país, recogiendo las características propias o específicas en cada uno de ellos. Solo así se podrán construir estadísticas precisas del sector que permitan medir y valorar su dimensión, de forma que se puedan establecer acciones políticas específicas que permitan aprovechar la riqueza y diversidad de las empresas sociales.

\section{7.- Bibliografía}

BORZAGA, C. \& NOGALES, R. (2013): Social enterprise definition and legislation, propuesta para el subgrupo GECES.

BORZAGA, C., SALVATORI, G., BODINI, R. \& GALERA, G. (2013): Social Economy and Social Entrepreneurship, Social Europe Guide, vol. 4, Comisión Europea.

CAFAGGI, F. \& IAMICELI, P. (2008): "Frontiers in the Legal Structures and Legislation of Social Enterprise in Europe: A Comparative Analysis", EUI Working Paper, no. 2008/16.

CHILD, C. (2015): "Tip of the iceberg. The Nonprofit Underpinnings of For-Profit Social Enterprise", Nonprofit and Voluntary Sector Quartely, 217-237.

DEES, J.G. \& ANDERSON, B. (2006): "Framing a Theory of Social Entrepreneurship: Building on Two Schools of Practice and Thought", Research on Social Entrepreneurship, ARNOVA Occasional Paper Series, 1 (3), 39-66.

DEFOURNY, J. (2014): "From third sector to social enterprise. A European research trajectory". In: Defourny, J., Hulgard, L., Pestoff, V., Social Enterprise and the Third Sector, New York, Routledge, 17-41.

DEFOURNY, J. \& NYSSENS, M. (Eds.) (2008): "Social Enterprise in Europe: recent trends and developments", EMES Working Paper, 08/01.

DEFOURNY, J. \& NYSSENS, M. (2014): "The EMES approach of social enterprise in a comparative perspective". In: Defourny, J., Hulgard, L., Pestoff, V. (Eds.), Social Enterprise and the Third Sector, 42-65.

DEFOURNY, J., HULGARD, L. \& PESTOFF, V. (Eds.) (2014): Social Enterprise and the Third Sector, London and New York, Routledge. 
DOERINGER, M.F. (2010): "Fostering Social Enterprise: A historical and international analysis", Duke Journal of Comparative \& International Law, 20, 291-329.

DOHERTY, B., HAUGH, H. \& LYON F. (2014), "Social Enterprises as Hybrid Organizations: A Review and Research Agenda", International Journal of Management Reviews, 16, 417-436.

EUROPEAN COMMISSION (2014): A map of social enterprises and their eco-systems in Europe, Directorate General for Employment, Social Affairs and Inclusion, B-1049, Bruselas.

FISAC, R. \& MORENO, A. (2015), "La empresa social: marco conceptual, contexto e información", Documentos AECA Serie responsabilidad Social Corporativa, $n^{\circ} 9$.

GALERA, G. \& BORZAGA, C. (2009): "Social Enterprise. An international overview of its conceptual evolution and legal implementation", Social Enterprise Journal, 5 (3), 201-228.

GILBERT, N. (2002): Transformation of the Welfare State. The silent surrender of public responsibility, Oxford: Oxford University Press.

HECKL, E. (Coord.) (2007): Study on Practices and Policies in the Social Enterprise Sector in Europe, Final Report, Austrian Institute for SME Research, Viena.

HUYBRECHTS, B., SYBILLE, M. \& RIJPENS, J. (2014): "Explaining stakeholder involvement in social enterprise governance through resources and legitimacy". In: Defourny, J., Hulgard, L., Pestoff, V. Social Enterprise and the Third Sector, Oxon y New York, Routledge, 157-175.

JOHNSON, T. \& SPEAR, T. (2006): "Social Enterprise. An International Literaure Review", SBS/SEnU, London, GHK.

KERLIN, J. (2013): "Defining Social Enterprise Across Different Contexts: A Conceptual Framework Based on Institutional Factors", Nonprofit and Voluntary Sector Quarterly, 42(1), 84-108.

MASON, C. (2009): "Governance and SEs". In: Doerthy, B. et al. (Eds.), Management of Social Enterprises, London, SAGE.

MONZÓN, J.L., ANTUÑANO, I. \& MURGUI, S. (2014): Informe sobre el impacto económico y social de los Centros Especiales de Empleo en España, Resumen ejecutivo, Fundación ONCE.

O'CONNOR, P. \& MEINHARD, A. (2014): "Work Integration Social Enterprises (WISEs): Their Potential Contribution to Labor Market (Re-) Integration of At Risk Populations", Centre for Voluntary Studies Working Paper Series, 2014(2).

PARLAMENTO EUROPEO (2012): Informe sobre la Iniciativa en favor del emprendimiento, Comisión de Empleo y Asuntos Sociales, A7-0305/2012.

PHILLS, J., DEIGLMEIER, K. \& MILLER, D. (2008): "Rediscovering Social Innovation”, Stanford Social Innovation Review, Fall 2008, 34-43. 
PRIEDE, T., LÓPEZ-CÓZAR, C. \& RODRIGUEZ, A. (2014): "Análisis del marco económico-jurídico específico para los emprendedores sociales. Un estudio comparativo entre diversos países", CIRIEC-España, Revista de Economía Pública, Social y Cooperativa, 80, 5-28.

RIDLEY-DUFF, R. \& BULL, M. (2011): "Defining Social Enterprise". In: Ridley-Duff, R., Bull, M. Understanding Social Enterprise. Theory \& Practice, London, SAGE Publications Ltd, 56-81.

RIDLEY-DUFF, R. \& SOUTHCOMBE, C. (2012): "The Social Enterprise Mark: a critical revision of its conceptual dimensions", número especial de la edición 'Critical Perspectives on Social Enterprise', Enterprise Journal, 8 (3), 178-200.

SALAMON, L., ANHEIER, H., LIST, R., TOEPLER, S., SOKOLOWSKI, S. \& Associates (2004): Global civil society: Dimensions of the nonprofit sector (vol. 2), Bloomfield, CT: Kumarian Press.

SCHÖNING, M., NOBLE, A., HEINECKE, A., ACHLEITNER, A. \& MAYER, J. (2012): The Governance of Social Enterprises, Schwab Foundation for Social Entrepreneurship, World Economic Forum.

SOCIAS, A. \& HORRACH, P. (2012): "Social responsibility and accountability in work integration social enterprise. The case of the Balearic Islands", CIRIEC-España, Revista de Economía Pública, Social y Cooperativa, 75, 251-276.

SPEAR, R., CORNFORTH, C. \& AIKEN, M. (2009): "The Governance Challenges of Social Enterprises: Evidence from a UK Empirical Study", Annals of Public and Cooperative Economics, 80:2, 247273.

TEASDALE, S. (2010): "What's in a name? The construction of social Enterprise", Public Administration Committee Conference, Nottingham Trent University, 8th September 2010.

THESIS, B. \& VENCHEVA, B. (2012): "Social Enterprises in UK and Italy: Resource Mix and Legal Framework Analysis", Erasmus Universiteit Rotterdam, 8/2012.

YOUNG, D. \& LACY, J. (2012): "Defining the Universe of Social Enterprise: Competing Metaphors", Andrew Young School of Policy Studies, Research Paper Series, Working Paper 12-25.

YOUNG, D. (1986): "Entrepreneurship and the Behavior of Non-profit Organizations: Elements of a Theory". In: Rose-Ackeman, S. (Eds.), The Economics on Non-profit Institutions, New York, Oxford University Press, 161-184. 